\title{
Health behaviours in emerging adulthood: Their relationship with perceived maternal and paternal parental attitudes and the mediating role of self-efficacy
}

\section{BACKGROUND}

The present research examined the mediating role of self-efficacy in the association between perceived maternal and paternal parental attitudes and health behaviours of males and females in emerging adulthood. Parental attitudes shape children's self-esteem, positive self-image, and self-competence. This may affect their physical health and health behaviours throughout their lives.

\section{PARTICIPANTS AND PROCEDURE}

A total of 147 (mean age: $19.70, S D=0.85,68.7 \%$ females) participants took part in the study. They completed several questionnaires measuring health behaviours, perceived parental attitudes, and self-efficacy: the Inventory of Health Behaviours, the Retrospective Assessment of Parental Attitude, and the General Self-Efficacy Scale.

\section{RESULTS}

We found that that female participants exhibited healthier eating habits but lower self-efficacy than male partic- ipants did. Accepting and autonomy granting maternal and paternal parental attitudes predicted a positive health attitude (of both male and female participants), preventive behaviours (of male participants), and healthy eating habits (of male participants). As predicted, emerging adults' self-efficacy mediated the relationship between their health behaviours and perceived parental attitudes. However, the mediation patterns were different for female and male participants.

\section{CONCLUSIONS}

The quality of perceived parental attitudes and self-efficacy are important for health-related lifestyle choices among emerging adults. Mothers and fathers may play different roles in the formation of health behaviours.

\section{KEY WORDS}

parental attitudes; health behaviours; self-efficacy; emerging adulthood

ORGANISATION - Institute of Psychology, University of Gdansk, Poland

AUthors' CONTRiButions - A: Study design - B: Data collection - C: Statistical analysis - D: Data interpretation .

E: Manuscript preparation · F: Literature search · G: Funds collection

CORResPonding AUthor - Anna Maria Jankowska, Ph.D., Institute of Psychology, University of Gdansk,

4 Bażyńskiego Str., 80-309 Gdansk, Poland, e-mail: a.jankowska@ug.edu.pl

to Cite this ARTICle - Jankowska, A., M., Łockiewicz, M., Dykalska-Bieck, D., Łada, A., Owoc, W., \& Stańczykowski D.

(2018). Health behaviours in emerging adulthood: Their relationship with perceived maternal and paternal parental

attitudes and the mediating role of self-efficacy. Health Psychology Report, 6(1), 94-108. doi: https://doi.org/10.5114/ hpr.2018.71202

RECEIVED 29.08.2017 · REVIEWED 07.09.2017 · ACCEPTED 20.09.2017 · PUBLISHED 08.11.2017 


\section{BACKGROUND}

Research on emerging adulthood, though still scarce, suggests that this period in life involves many health risk factors due to a modern, Western culture lifestyle (Janssen, Katzmarzyk, Boyce, King, \& Pickett, 2004) and age-typical tendencies to engage in risk behaviours (Furstenberg, 2006; Kessler, Mickelson, Waltes, Zhao, \& Hamilton, 2004; National Survey on Drug Use and Health, 2011). Preliminary studies indicate family and cognition as predictors of health outcomes in emerging adults (Donnelly, Renk, \& McKinney, 2013).

In the last decades, new trends in the behaviour of young people aged 18-25 years have emerged in highly developed societies. The time in which young adults undertake tasks typical of adulthood, such as marriage, parenthood, or permanent employment, has been delayed (Crocetti, Scrignaro, Sica, \& Magrin, 2012). This specific time of transition between adolescence and full adulthood is called emerging adulthood (Arnett, 2000), an age of possibilities, self-focus, and active testing of alternatives, especially concerning professional and romantic life (Arnett, 2004). Focused on their own development, emerging adults better understand who they are and what they want in life, and formulate their own plans for adulthood, which they constantly revise. This intense exploration and the accompanying instability are also connected with the process of identity exploration, which started in adolescence. Therefore, emerging adults experience a feeling of in-between adolescence and adulthood. Their lack of a sense of full adulthood results from not performing fully its three main challenges: independent decisions, accepting responsibility for them, and financial independence. The responsibility for these challenges is often co-shared by parents, though paradoxically, emerging adults usually already function beyond their direct control (Piotrowski, Brzezińska, \& Pietrzak, 2013). Freed from duties typical for adults, yet before making final commitments, they intensively test various possibilities, which can be a quite stressful and demanding process (Arnett, 2013). Diminished parental control and busy lifestyle typical of this period could, therefore, have implications for the health behaviours of emerging adults.

Health behaviours are personal, conscious actions that directly or indirectly affect the state of one's health. They are purposeful, related to one's lifestyle and daily habits (e.g. amount of sleep, eating habits, physical activity, amount of consumed alcohol, and using psychoactive substances). These behaviours may be either positive or negative (Woynarowska, 2010). Decisions regarding health behaviours are based on both objective knowledge about the factors that determine health or disease and on subjective beliefs about them (Sęk, 2000). For instance, attitudes towards health behaviours may depend on gender and different gender socialisation processes among boys and girls, e.g. eating healthy food and dieting are considered by some men as feminine, not masculine behaviours, and are therefore rejected (El Ansari, Suominen, \& Samara, 2015; Wardle et al., 2004).

Undoubtedly, parents are important agents in the process of acquiring and shaping health behaviours. They apply different health practices while caring for a child (e.g. regarding quality and frequency of meals, sleep duration and sleep habits, amount of time spent watching TV), and when a child's cognitive and motor development progress, they provide instruction and training on health practices (Ray, Kalland, Lehto, \& Roos, 2013). Subsequently, adolescence is a critical moment to consolidate the habits and attitudes towards health activities (Woynarowska, 2010; Wojtczak, 2009). In the period of emerging adulthood, when young people achieve considerable autonomy (Arnett, 2004; Shanahan, 2000), they gradually assume full responsibility for their life, including their own health and the health of others, e.g. of aging parents (Weiner, Roloff, \& Pusateri, 2014). They start to use diverse health practices on their own, including possibly those demonstrated and/or promoted by their parents. Therefore, the behaviour and attitudes of parents can be of great importance for the quality of health of emerging adults (Kanter-Agliata \& Renk, 2009; Niemeier, Duan, Shang, \& Yang, 2017).

The impact of positive parental health practices on favourable health behaviours of the child is strengthened by parental attitudes of warmth and responsiveness (Ray et al., 2013). Parental attitudes determine the way in which parents build relationships with their children, and how they react in certain parenting situations (Lipowska, Lipowski, \& Pawlicka, 2016). Studies indicate that parental attitudes influence the psychological development of children and adolescents and their ability to adapt and function properly. Parents are the first and most important source of emotional support, but also of self-knowledge and self-acceptance. Positive parental attitudes shape children's self-esteem, positive self-image, and self-competence (Lord, Eccles, \& McCarthy, 1994; Wissink, Dekovic, \& Meijer, 2006), which affect their mental and physical health (Donnelly et al., 2013; Trzesniewski et al., 2006). For instance, children of warm, accepting, and sensitive parents eat more fruit and vegetables (Kremers, Bridge, de Vries, \& Engels, 2003; Lytle et al., 2003) and are less likely to use alcohol during adolescence (Kuendig \& Kuntsche, 2006; van der Vorst, Engels, Meeus, \& Dekovic, 2006). However, children of parents not involved in parenting, emotionally cold, and/or too controlling, regardless of their age, struggle with multiple health issues. For example, a controlling attitude adversely affects the adaptation of children with diabetes to their disease and lowers their treatment effectiveness (Butler, Skin-
Health behaviours in emerging adulthood and the mediating role of self-efficacy 
Anna Maria Jankowska,

Marta Łockiewicz,

Dorota

Dykalska-Bieck,

Ariadna Łada,

Weronika Owoc,

Dawid

Stańczykowski ner, Gelfand, Berg, \& Wiebe, 2007), and increases the likelihood of adolescents engaging in activities which worsen their health (Helgeson et al., 2013). An overprotective attitude contributes to female weight control difficulties (Turner, Rose, \& Cooper, 2005). Uninvolved parenting impacts greater weight fluctuations in a short-term period, higher body weight (Goldschmidt, Wall, \& Zhang 2016; Thomas, Hypponen, \& Power, 2008), and higher level of risk behaviours in adolescents (Nelson, Padilla-Walker, \& Nielson, 2015), as well as many serious health conditions (e.g. cardiovascular disease, hypertension, duodenal ulcer, and alcoholism) (Russek \& Schwartz, 1997), anxieties (Wolfradt, Hempel, \& Miles, 2003), and a tendency to abuse alcohol and drugs (Joyce et al., 1994) in adults.

The above examples demonstrate that parental attitudes may influence health behaviours of emerging adults (Bradley-Geist \& Olson-Buchanan, 2014). The literature also indicates the role of the sense of self-efficacy in the health aspects of emerging adulthood.

The sense of self-efficacy refers to one's beliefs about one's effectiveness in dealing with task completion. In other words, it is a personal belief in one's ability to plan, organise, control, and implement a purposeful action (Bandura, 1997). The conviction of how well you can cope with the task determines the amount of effort that you invest in starting and continuing an action and persistence in overcoming potential difficulties on the way to your goal (Luszczyńska \& Schwarzer, 2005; Schwarzer, 2008). Beliefs about one's self-efficacy are formed in childhood and adolescence under the influence of one's own experiences (mastery experiences), observing the actions of important persons (vicarious experiences/modelling) or feedback given about us (verbal persuasion) (Bandura, 1993, 1997). Therefore, parents play a key role in the emergence of self-efficacy. The parental attitude that guarantees acceptance, encouragement to become independent, and open communication (Bong, 2008; Pomerantz \& Eaton, 2001) is of great importance for positive development of self-efficacy. Adolescents who perceive their parents as warm, dedicated, and allowing for an age-appropriate level of autonomy and independence manifest higher levels of self-efficacy than their peers who evaluate their parents less favourably (Ingoldsby, Schvaneveldt, Supple, \& Bush, 2004). Nidith and Varela (2012) reported that a rejecting maternal (but not paternal) attitude predicted low self-efficacy, which mediated the relationship between maternal rejecting attitude and an increased level of anxiety in teenagers. Many other studies also point to the negative impact of a maternal overprotective attitude on children's self-efficacy (Bradley-Geist et al., 2014), excessive dependence on others, and higher levels of neuroticism (Odenweller, Booth-Butterfield, \& Weber, 2014). As self-efficacy is essential to achieve the objectives (Frydenberg \& Lewis, 2009), it also affects the persistence and effective coping with situations involving health. Self-efficacy, therefore, affects the quality of self-care and healthy lifestyle behaviours (Binay \& Yiğit, 2016; Zhou, Sun, Knoll, Hamilton, \& Schwarzer, 2015), including, for example, regular exercise (Dishman et al., 2004; Dwyer et al., 2012; Wienert, Kuhlmann, \& Lippke, 2015), preventive behaviours (Schwarzer \& Renner, 2000), or perseverance in coping with the effects of chronic diseases (Berg et al., 2011; Helgeson, Honcharuk, Becker, Escobar, \& Siminerio, 2011).

\section{PARTICIPANTS AND PROCEDURE}

\section{THE AIM OF THE RESEARCH}

In our study, we were interested in investigating health behaviours of emerging adults because this population is (a) still in the process of embracing their independent self-care and health practices, while yet not fully accepting all responsibilities for their actions and well-being, and (b) they become more vulnerable to the modern lifestyle health-related risks than earlier in their childhood and adolescence (Janssen et al., 2004). Primarily, we were wondering if there are any gender differences in health behaviour of emerging adults because previous research indicates that gender stereotypes may contribute to health-related behaviours (Wardle et al., 2004). Furthermore, as preliminary studies indicate family and cognition as predictors of health outcomes (Donnelly et al., 2013), we examined if they are associated with how female and male emerging adults perceive their parents' parental attitudes, and if this relationship is mediated by emerging adults' self-efficacy.

We assumed that females might be more concerned about maintaining health behaviours (H1). Moreover, we hypothesised that parental attitudes influence health behaviours and self-efficacy of male and female emerging adults (H2). Specifically, we assumed that accepting and autonomy granting parental attitudes predict positive health behaviours, whereas demanding and overprotecting attitudes predict negative ones (H3); self-efficacy is positively and significantly associated with positive health behaviours (H4); and self-efficacy mediates the relationship between parental attitudes and health behaviours (H5). To our knowledge, this is the first study that directly measures the mediating role of self-efficacy between health behaviours and perceived parental attitudes of parents of the same and opposite gender in female and male emerging adults.

\section{METHODS}

In total, 101 (68.7\%) female and $46(31.3 \%)$ male social sciences university students in emerging adulthood 
(between 19 and 24 years old, matched between genders; mean age for females $=19.65$ years, $S D=0.82$, mean age for males $=19.8$ years, $S D=0.91,(t(145)$ $=1.00, p=.318)$ participated. A general health survey that we developed for the study indicated that $36(78.3 \%)$ males and $86(85.1 \%)$ females regarded themselves as being a generally healthy person. However, $17(37.0 \%)$ males and $33(32.7 \%)$ females declared suffering from a chronic illness, 10 (21.7\%) males and six (5.9\%) females reported having a disability, and $15(32.6 \%)$ males and 36 (35.6\%) females took over-the-counter and/or prescription drugs regularly. Moreover, 33 (71.1\%) males and $61(60.4 \%)$ females reported that a close relative/best friend suffered from a serious illness, and $23(50.0 \%)$ males and $52(51.5 \%)$ females lost a close relative/best friend to illness, or their close relatives/best friends became disabled as a result of health negligence. After providing verbal consent, each respondent completed a set of self-reporting questionnaires designed to evaluate health behaviours, perceived parental attitudes, and self-efficacy.

The Inventory of Health Behaviours (Juczynski, 2009) consists of 24 statements describing health-related behaviours: correct eating habits (e.g. eating fruit, vegetables, and wholegrain products), preventive behaviours (following health recommendations and seeking information about maintaining good health), a positive mental attitude (maintaining psychological well-being by avoiding stress, difficult emotions, or woeful situations), and health practices (daily basis activities that impact overall health outcomes like sleeping habits, leisure, and physical activity). The overall intensity and the intensity of each category of health-related behaviours is evaluated on the basis of their self-reported frequency, rated on a five-point scale, where 1 means almost never, and 5 means almost always. The higher the value for the general index and for the four factors, the higher the level of the declared health behaviour $(\min =24, \max$ $=120$ points). Test reliability is: .85 for the total score and from .6 to .65 for the four subscales.

Retrospective Assessment of Parental Attitudes (Plopa, 2008) consists of two separate, 50-statement questionnaires to assess parental attitudes of a father and a mother. The respondent rates the statements using a five-point scale ranging from "she (he) was definitely like that and behaved this way" to "she (he) was definitely not like that and did not behave this way". The tool allows for a retrospective evaluation of five parental attitudes: accepting, demanding, autonomy granting, inconsequent, and overprotective. A higher score indicates higher intensity of a specific parental attitude. High score in (a), the accepting attitude, represents a close emotional relationship between a parent and a child, the parent likes the child as he or she is, supports and cares for him/her, allows for open, two-way communication with the child. High score in (b), the demanding attitude, represents a parent who is cold, aloof, and controlling. The parent expects a lot from the child, while ignoring his or her capabilities, preferences, and developmental needs. The parent does not allow for two-way communication with the child and requires total obedience. High score in (c), the autonomy granting attitude, represents a parent who respects and supports the child's emerging need for independence and separation from a parent who behaves flexibly and takes into account the developmental needs of the child. High score in (d), the inconsequent attitude, represents a parent whose behaviours are changeable, often unpredictable and extreme, which often leads to the child's withdrawal from the relationship with the parent. High score in (e), the overprotecting attitude, represents a parent who sees their child as helpless, feels a constant urge to care excessively for the child, and engage in all his or her spheres of life, ignoring the child's need for autonomy and independence. Test reliability is from .93 to .86 for the maternal scale, and from .90 to .84 for the paternal scale.

The General Self-Efficacy Scale (Schwarzer \& Jerusalem, 1995) consists of 10 statements constituting a single factor - self-efficacy. The higher the score, the greater the belief in one's effectiveness to cope with difficult situations and obstacles. The internal reliability for the scale (Cronbach's $\alpha$ ) is between .76 and .90 .

\section{RESULTS}

\section{DIFFERENCES IN HEALTH BEHAVIOURS, PERCEIVED PARENTAL ATTITUDES, AND SELF-EFFICACY BETWEEN MALE AND FEMALE EMERGING ADULTS}

The Mann-Whitney $U$ test for independent samples (Table 1) showed that females $(M d n=20)$ exhibited more healthy eating habits as compared to males $(M d n=18 ; U=1589.5, Z=3.07, p=.002, r=.25)$, but lower self-efficacy $(M d n=30$ for females, $M d n=$ 32 for males; $U=1375.5, Z=2.45, p=.014, r=.20)$. Male and female participants did not differ in other aspects of health behaviours (preventive behaviours, positive mental attitude, and health practices) or how they retrospectively assessed their mothers' and fathers' parental attitudes.

\section{CORRELATIONS BETWEEN VARIABLES}

In order to examine the relationship between health behaviours, the retrospective assessment of parental attitudes (mother's and father's accepting, demanding, autonomy granting, inconsequent, and overprotective attitudes), and self-efficacy in male and
Health behaviours in emerging adulthood and the mediating role of self-efficacy 
Table 1

Descriptive characteristic of the compared groups: health behaviours, retrospective assessment of parental attitudes, and self-efficacy

Anna Maria

Jankowska, Marta Łockiewicz, Dorota

Dykalska-Bieck, Ariadna Łada, Weronika Owoc, Dawid Stańczykowski

$$
\text { Males Females }
$$

Inventory of Health Behaviours

$\begin{array}{lll}\text { Healthy eating habits } & M d n=18 & M d n=20 \\ \text { Preventive behaviours } & M d n=17 & M d n=18 \\ \text { Positive mental attitude } & M d n=20 & M d n=19 \\ \text { Health practices } & M d n=20 & M d n=19 \\ \text { Total score } & M d n=74.5 & M d n=77\end{array}$

Retrospective Assessment of Parental Attitudes

$$
\begin{gathered}
U=1589.5, Z=3.07, \\
p=.002, r=.25 \\
U=1954, Z=1.55, \\
p=.122, r=.13 \\
U=2240.5, Z=0.35, \\
p=.730, r=.03 \\
U=2102, Z=0.93, \\
p=.354, r=.08 \\
U=2102, Z=0.93, \\
p=.354, r=.08
\end{gathered}
$$

Mother's attitude

$\begin{array}{lll}\text { Accepting } & M d n=39.5 & M d n=40 \\ \text { Demanding } & M d n=28 & M d n=25 \\ \text { Autonomy granting } & M d n=40 & M d n=39 \\ \text { Inconsequent } & M d n=26 & M d n=23 \\ \text { Overprotective } & M d n=36.5 & M d n=36\end{array}$

$$
\begin{gathered}
U=2212, Z=0.464, \\
p=.642, r=.04 \\
U=2007, Z=1.321, \\
p=.186, r=.11 \\
U=2167.5, Z=0.650 \\
p=.515, r=.05 \\
U=2096, Z=0.949 \\
p=.343, r=.08 \\
U=2172.5, Z=0.630 \\
p=.592, r=.05
\end{gathered}
$$

Father's attitude

$\begin{array}{lll}\text { Accepting } & M d n=34 & M d n=36 \\ \text { Demanding } & M d n=29 & M d n=27 \\ \text { Autonomy granting } & M d n=37 & M d n=37 \\ \text { Inconsequent } & M d n=29 & M d n=26 \\ \text { Overprotective } & M d n=25.5 & M d n=25\end{array}$

$$
U=1968, Z=0.190,
$$$$
p=.850, r=.02
$$$$
U=1810, Z=0.920,
$$$$
p=.358, r=.08
$$$$
U=1988.5, Z=0.095 \text {, }
$$$$
p=.924, r=.01
$$$$
U=1804, Z=0.947 \text {, }
$$$$
p=.343, r=.08
$$$$
U=1991, Z=0.081 \text {, }
$$$$
p=.936, r=.01
$$

\section{General Self-Efficacy Scale}


Table 2

Correlations between health behaviours, the retrospective assessment of parental attitudes and self-efficacy in emerging adults

\begin{tabular}{|c|c|c|c|c|c|c|c|c|c|c|}
\hline & \multicolumn{2}{|c|}{$\begin{array}{c}\text { Healthy } \\
\text { eating habits }\end{array}$} & \multicolumn{2}{|c|}{$\begin{array}{l}\text { Preventive } \\
\text { behaviours }\end{array}$} & \multicolumn{2}{|c|}{$\begin{array}{c}\text { Positive } \\
\text { mental attitude }\end{array}$} & \multicolumn{2}{|c|}{$\begin{array}{c}\text { Health } \\
\text { practices }\end{array}$} & \multicolumn{2}{|c|}{ Self-efficacy } \\
\hline & Males & Females & Males & Females & Males & Females & Males & Females & Males & Females \\
\hline \multicolumn{11}{|l|}{ Mother's attitude } \\
\hline Accepting & & & & & & .22 & & & & $32^{*}$ \\
\hline $\begin{array}{l}\text { Autonomy grant- } \\
\text { ing }\end{array}$ & & & & & & .22 & & & .30 & $.28^{*}$ \\
\hline Inconsequent & & & & & & -.20 & -.36 & & & -.24 \\
\hline \multicolumn{11}{|l|}{ Father's attitude } \\
\hline Accepting & .37 & & .37 & & $.53^{*}$ & $.32^{*}$ & & & & \\
\hline Demanding & & & -.37 & & & & & & & \\
\hline $\begin{array}{l}\text { Autonomy grant- } \\
\text { ing }\end{array}$ & & & $.48^{*}$ & & $.44^{*}$ & $.28^{*}$ & & & & \\
\hline Inconsequent & & & -.32 & & & $-.29^{*}$ & & & & \\
\hline Self-efficacy & $.46^{*}$ & $.26^{*}$ & & $.27^{*}$ & $.48^{*}$ & $.42^{*}$ & & & & \\
\hline
\end{tabular}

Note. All marked correlations are significant at $p \leq .01$ level. All unmarked correlations are significant at $p \leq .05$ level. Only significant correlations are included.

female emerging adults, we calculated Spearman's rho correlations (Table 2).

\section{HEALTH BEHAVIOURS \\ AND THE RETROSPECTIVE ASSESSMENT OF MATERNAL PARENTAL ATTITUDES}

We found that in female participants, positive mental attitude was weakly correlated with accepting, autonomy granting (positively), and inconsequent attitudes (negatively). In male participants, maternal inconsequence was moderately negatively correlated with health practices.

\section{HEALTH BEHAVIOURS \\ AND THE RETROSPECTIVE ASSESSMENT OF PATERNAL PARENTAL ATTITUDES}

We found that in female participants, positive mental attitude was moderately correlated with accepting, and weakly with autonomy granting (positively), and inconsequent (negatively) attitude. In male participants, preventive behaviours were moderately correlated with accepting, autonomy granting (positively), and demanding and inconsequent (negatively) attitude. Positive mental attitude was strongly correlated with accepting (positively) and moderately with autonomy granting (positively) attitude, and healthy eating habits moderately with accepting attitude.

\section{HEALTH BEHAVIOURS AND SELF-EFFICACY}

We found that in female students, self-efficacy was correlated positively with healthy eating habits, preventive behaviours (weakly), and positive mental attitude (moderately). In male students, self-efficacy was correlated positively with healthy eating habits and positive mental attitude (moderately).

\section{SELF-EFFICACY AND THE RETROSPECTIVE ASSESSMENT OF PARENTAL ATTITUDES}

We found that in female students, self-efficacy was moderately correlated with the mother's accepting (positively) attitude, and weakly with the mother's autonomy granting (positively) and inconsequence (negatively). In male students, self-efficacy was moderately correlated with the mother's autonomy granting (positively) attitude. No correlation was found between self-efficacy and the retrospective assessment of paternal attitudes.

\section{REGRESSION}

In female participants positive mental attitude was influenced by maternal accepting $[B=.08(.04)$, $\left.p=.040, R^{2}=.04, F(1,96)=4.33\right]$ and autonomy granting $\left[B=.10(.05), p=.037, R^{2}=.04, F(1,99)=4.49\right]$, but not inconsequent attitude $[B=-.07(.04), p=.073$, $R^{2}=.03, F(1,99)=3.27$ ], and by paternal accepting
Health behaviours in emerging adulthood and the mediating role of self-efficacy 
Anna Maria

Jankowska,

Marta Łockiewicz,

Dorota

Dykalska-Bieck,

Ariadna Łada,

Weronika Owoc,

Dawid

Stańczykowski
$\left[B=.10(.03), p=.002, R^{2}=.09, F(1,96)=9.65\right], \mathrm{au}^{-}$ tonomy granting $\left[B=.11(.04), p=.008, R^{2}=.07\right.$, $F(1,96)=7.40]$, and inconsequent attitude $[B=-.12$ (.04), $\left.p=.001, R^{2}=.10, F(1,96)=10.99\right]$.

In male participants, health practices were predicted by maternal inconsequent attitude $[B=-.13$ (.06), $\left.p=.032, R^{2}=.10, F(1,44)=4.91\right]$. Preventive behaviours were influenced positively by paternal accepting attitude $\left[B=.16(.07), p=.027, R^{2}=.12\right.$, $F(1,39)=5.30]$ and paternal autonomy granting attitude $\left[B=.18(.07), p=.019, R^{2}=.13, F(1,39)=6.00\right]$, and negatively by paternal demanding attitude $\left[B=-.14\right.$ (.07), $\left.p=.048, R^{2}=.10, F(1,39)=4.19\right]$, but not inconsequent attitude $[B=-.11(.07), p=.089$, $\left.R^{2}=.07, F(1,39)=3.04\right]$. Positive mental attitude was predicted by paternal accepting $[B=.29(.08)$, $\left.p=.001, R^{2}=.23, F(1,39)=11.88\right]$ and autonomy granting attitude $\left[B=.18(.09), p=.055, R^{2}=.09\right.$, $F(1,39)=3.93]$. Healthy eating habits were influenced by paternal accepting attitude $[B=.19(.09), p=.036$, $\left.R^{2}=.11, F(1,39)=4.71\right]$.

\section{MEDIATION}

To test the hypothesis that the relationship between the retrospective assessment of parental attitudes (mother's and father's accepting, demanding, autonomy granting, inconsequent, and overprotective atti- tude) and health behaviours is mediated by self-efficacy, we calculated a PROCESS (model 4; by Hayes, 2013) mediation analysis with bootstrap resamples.

In female participants, maternal accepting attitude was indirectly linked to a positive mental attitude. The participants who felt that their mother's attitude was more accepting reported higher self-efficacy $(\mathrm{a}=$ .11), which was linked to a higher positive mental attitude $(\mathrm{b}=.24)$. Adjusted confidence intervals for an indirect effect $(\mathrm{ab}=.03)$ based on 5000 bootstrap resamples were above zero (from .000 to .080). However, there was no direct effect of the impact of maternal accepting attitude on a positive mental attitude of the female emerging adults $\left(c^{\prime}=.05, p=.170\right)$.

In female participants, maternal autonomy granting attitude was indirectly linked to a positive mental attitude. The participants who felt that their mothers supported and accepted their autonomy reported higher self-efficacy $(\mathrm{a}=.11)$, which was linked to a higher positive mental attitude $(b=.25)$. Adjusted confidence intervals for an indirect effect $(a b=.03)$ based on 5000 bootstrap resamples were above zero (from .000 to .020). However, there was no direct effect of the impact of maternal acceptance/rejection on a positive mental attitude of the female emerging adults (c' $=.07, p=.110)$.

In male participants, paternal accepting attitude was indirectly linked to a positive mental attitude. The participants who felt their fathers' acceptance

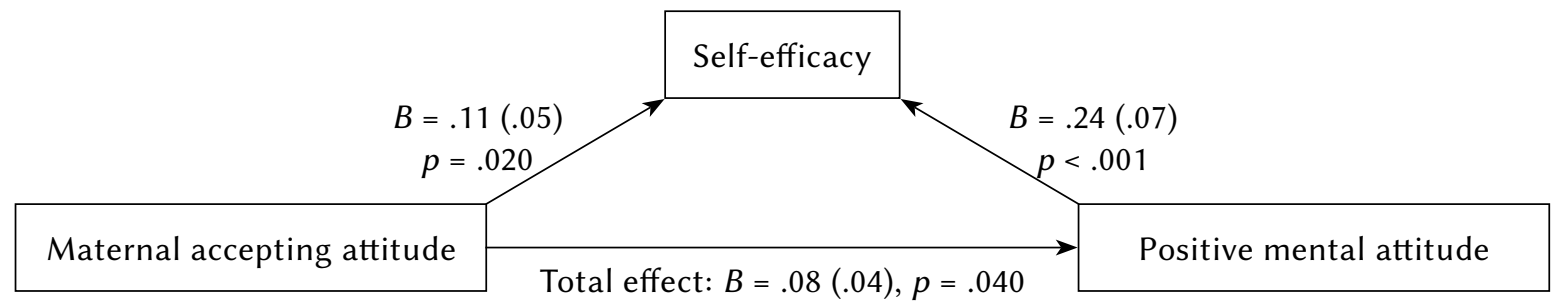

Direct effect: $B=.05(.04), p=.170$

Indirect effect: $B=.03(.02)$

Lower $\mathrm{Cl} .000$, Upper $\mathrm{Cl} .080$

Note. Standard errors in parentheses; number of bootstrap resamples: 5000. Bootstrap $\mathrm{Cl}$ method: biased corrected; $95 \%$.

Figure 1. Retrospective assessment of maternal accepting attitude, self-efficacy, and positive mental attitude in female students.

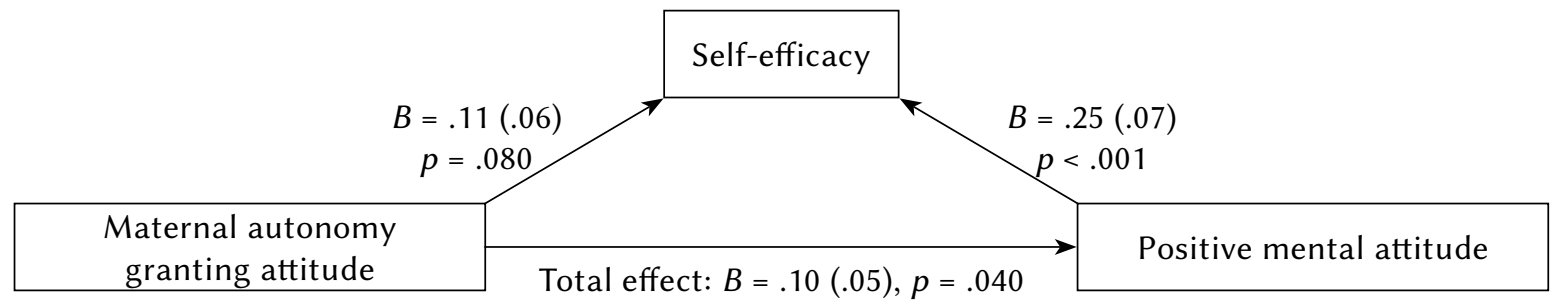

Direct effect: $B=.07(.04), p=.110$

Indirect effect: $B=.03(.02)$

Lower $\mathrm{Cl} .000$, Upper $\mathrm{Cl} .020$

Note. Standard errors in parentheses; number of bootstrap resamples: 5000. Bootstrap Cl method: biased corrected; $95 \%$.

Figure 2. Retrospective assessment of maternal autonomy granting attitude, self-efficacy, and positive mental attitude in female students. 


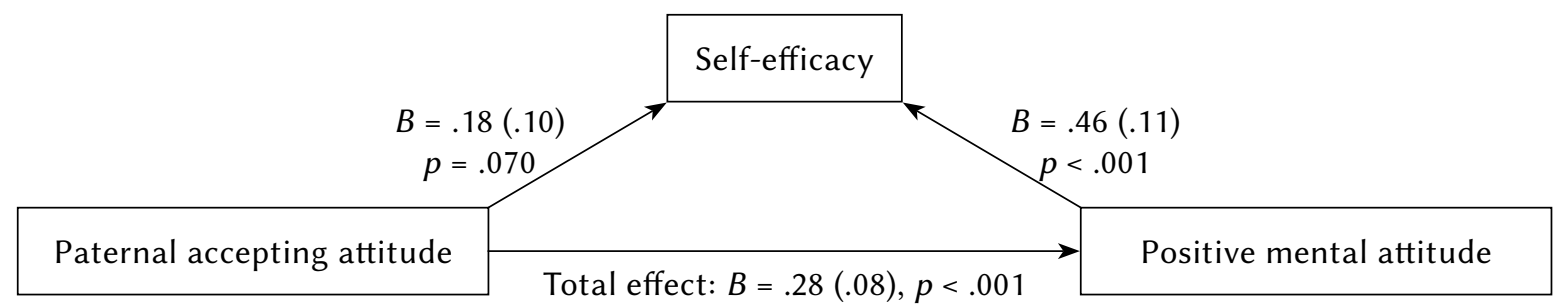

Direct effect: $B=.20(.07), p=.010$

Indirect effect: $B=.08(.05)$

Lower $\mathrm{Cl} .010$, Upper $\mathrm{Cl} .023$

Note. Standard errors in parentheses; number of bootstrap resamples: 5000 . Bootstrap CI method: biased corrected; $95 \%$.

Figure 3. Retrospective assessment of paternal accepting attitude, self-efficacy, and positive mental attitude in male students.

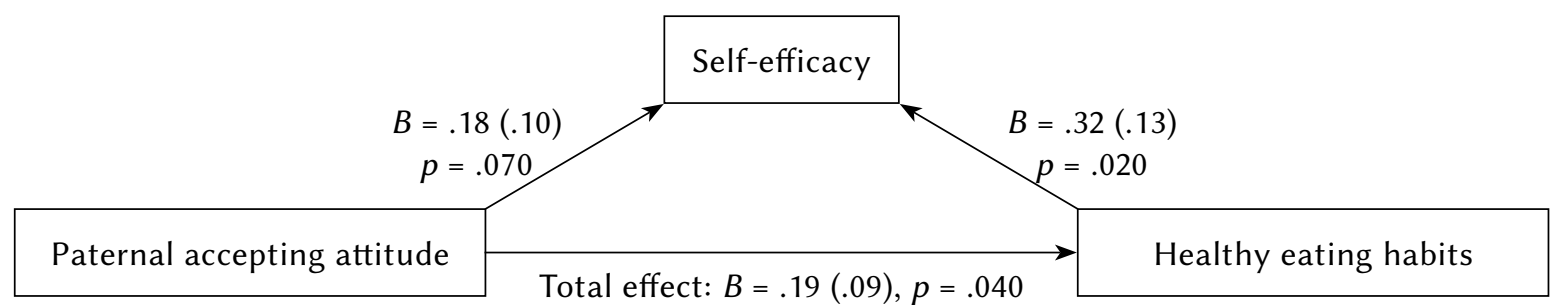

Direct effect: $B=.13(.08), p=.140$

Indirect effect: $B=.06(.04)$

Lower $\mathrm{Cl} .000$, Upper Cl .019

Note. Standard errors in parenthesEs; number of bootstrap resamples: 5000. Bootstrap Cl method: biased corrected; $95 \%$.

Figure 4. Retrospective assessment of paternal accepting attitude, self-efficacy, and healthy eating habits in male students.

reported higher self-efficacy $(\mathrm{a}=.18)$, which was linked to a higher positive mental attitude $(\mathrm{b}=.46)$. Adjusted confidence intervals for an indirect effect $(\mathrm{ab}=.08)$ based on 5000 bootstrap resamples were above zero (from .010 to .023). Moreover, there was also a direct effect of the impact of paternal accepting attitude on a positive mental attitude, showing that male students who perceived their fathers as accepting reported more positive mental attitudes $\left(c^{\prime}=.20\right.$, $p=.010)$.

In male participants, paternal accepting attitude was indirectly linked to healthy eating behaviours. The participants who felt their fathers' acceptance reported a higher self-efficacy $(\mathrm{a}=.18)$, which was linked to a higher positive mental attitude $(\mathrm{b}=.32)$. Adjusted confidence intervals for an indirect effect $(\mathrm{ab}=.06)$ based on 5000 bootstrap resamples were above zero (from .000 to .019). However, there was no direct effect of the impact of paternal accepting attitude on healthy eating habits $\left(c^{\prime}=.13, p=.140\right)$.

\section{DISCUSSION}

This study aimed to investigate gender differences in health behaviours in emerging adults, the association between their health behaviours and perceived parental attitudes, as well as the mediating role of self-efficacy.

\section{HEALTH BEHAVIOURS AND SELF-EFFICACY IN MALE AND FEMALE EMERGING ADULTS}

We noticed significant differences between the male and female participants in the declared health behaviours and self-efficacy. The male participants, compared with the female ones, cared less about a healthy, balanced diet but exhibited a higher sense of self-efficacy. In fact, the men believed that healthy eating habits should be more important for women (El Ansari et al., 2015; Wardle et al., 2004), who are usually more concerned about an attractive physical appearance and achieve it through dieting (Wardle et al., 2004). Furthermore, higher self-efficacy levels in male participants are consistent with the literature, too (Klassen \& Chiu, 2010). Our results can be explained by a different pattern of gender socialisation, as boys' social worth depends on their fitness and activity, and not on their appearance. Males more often treat their bodies as a process, not as an object (Franzoi et al., 2012), and this results in a lesser importance of one's appearance and in a satisfaction with one's body provided that it is adequately fit. Females, on the other hand, receive information that they are evaluated through the prism of their appearance and physical attractiveness quite early in the process of gender socialisation. Both boys and girls, as gender socialisation advances, begin to see themselves through the prism of social expectations associated
Health behaviours in emerging adulthood and the mediating role of self-efficacy 
with their gender. Fulfilling social expectations in accordance with gender stereotypes may be especially important during emerging adulthood, when young men and women more intensively engage in searching for a partner to start a family with. Thus, they care about fulfilling gender norms.

\section{PARENTAL ATTITUDES, HEALTH BEHAVIOURS,} AND THE MEDIATING ROLE OF SELF-EFFICACY

Anna Maria

Jankowska,

Marta Łockiewicz,

Dorota

Dykalska-Bieck,

Ariadna Łada,

Weronika Owoc,

Dawid

Stańczykowski

In our study, we noticed predominantly the influence of perceived accepting and autonomy granting parental attitudes on the emerging adults' health behaviours. This is consistent with the literature. According to the parental acceptance-rejection theory, parental and other attachment figures' acceptance is critical for the correct psychological development and adjustment of children, adolescents, and later adults (Khaleque \& Rohner, 2002). Parents who are warm and accept their children for who they are, who flexibly respond to their children's needs and encourage them to take up responsibilities (an autonomy granting attitude), raise children who are independent, self-assured, and have positive beliefs about their competences and self-efficacy (Bradley-Geist et al., 2014; Collins \& Laursen, 2006; Ingoldsby et al., 2004). This, consequently, has a positive effect on a wide range of behaviours, including health behaviours and preventive health behaviours (Riggs, Sakuma, \& Pentz, 2007) of both males and females (Mohamadian \& Ghannaee-Arani, 2014). Parental attitudes, independently of a child's gender, age, or culture, were found to be especially important for such health behaviours as maintaining a healthy body mass index (Berge, Wall, Loth, \& Neumark-Sztainer, 2010) and mood regulation (Rohner, Khaleque, \& Cournoyer, 2005). Children of affectionate and autonomy granting parents are more optimistic (Jackson, Pratt, Hunsberger, \& Pancer, 2005; Larzelere, Morris, \& Harrist, 2013), have better dietary habits (Goldschmidt et al., 2016), and have better health recommendation adherence (Shorer et al., 2011).

The results from previous research are also confirmed in our study, where parental attitudes and self-efficacy mainly predicted such health behaviours as positive mental attitude (of male and female participants), preventive behaviours, and healthy eating habits (of male participants). Furthermore, we noticed that self-efficacy not only determined health behaviours but, more importantly, it also mediated between health behaviours and perceived parental attitudes. Thus, we assume that the quality of parental attitudes influences their child's self-efficacy, which, in turn, determines the quality of health behaviours (positive vs. negative health behaviours). Emerging adults, whose parents support their autonomy and develop their confidence, tend to exhibit higher self-efficacy (Ingoldsby et al., 2004). Consequently, self-efficacy provides them with the sense of competence, control over one's life, and the ability to overcome challenges, which creates belief that effort invested in certain behaviours (e.g. dieting) will produce positive effects (e.g. lower BMI). Therefore, emerging adults with high self-efficacy are more likely to engage in positive rather than negative health behaviours (Binay et al., 2016; DuBois, Felner, Sherman, \& Bull, 1994; Hochhausen et al., 2007; Klein-Hessling, Lohaus, \& Ball, 2005; Posadzki, Stockl, Musonda, \& Tsouroufli, 2010).

In previous studies self-efficacy was a salient factor for effective weight control, refraining from excessive food intake (Francis \& Susman, 2009; GokeeLaRose, Gorin, \& Wing, 2009), managing preventive behaviors (Anderson, Winett, \& Wojcik, 2007; Cooper, Wells, \& Todd, 2004; Luszczyńska \& Schwarzer, 2003), and mood regulation (Bandura, Caprara, Barbaranelli, Gerbino, \& Pastorelli, 2003; Donnelly et al., 2013), which are also health behaviours that were predicted by self-efficacy in our study. Furthermore, Reed, Duncan, Lucier-Greer, Fixelle, and Ferraro (2016) found that self-efficacy is an important mediator between autonomy granting parenting and mood disorder and physical health among emerging adults. Interestingly, in our study self-efficacy mainly mediated the relationship between health behaviours and parental attitudes of a same-sex parent, which we discuss in the next paragraph.

\section{GENDER AND ASSOCIATION BETWEEN PERCEIVED PARENTAL ATTITUDES AND HEALTH BEHAVIOURS}

In our study, health behaviours of female emerging adults were determined by both maternal and paternal attitudes, while of male ones - primarily by paternal. These results suggest a father's particularly important role in shaping health behaviours, attitudes towards one's own body, and health in young men. Perhaps this effect is related to identity, which is developing intensively during emerging adulthood (Kroger, Martinussen, \& Marcia, 2010). In this period, young men explore their identity, especially their gender identity, and refer to their father's attitudes and beliefs. This assumption is confirmed by the finding that a father-son (but not a mother-son) relationship determines the identity exploration process for boys (Grotevant \& Cooper, 1985). Furthermore, identity exploration (Stolz, Barber, \& Olsen, 2005) and identity achievement in young adult men (e.g. Beyers \& Goossens, 2008) depend on the influence of accepting and autonomy granting paternal attitudes, and gender norms that young men identify with are closely associated with their health-related behaviours (Cohen \& Burger, 2000). Strong views 
about masculinity among young men predict a higher risk for sexually transmitted infections, substance abuse, or other risk behaviours, which, according to gender stereotypes, are considered typical and frequent for men (Courtenay 1998; Pulerwitz \& Barker, 2008). Health-risk behaviours (e.g. unprotected sex, substance abuse) may be considered by some men as evidence of true manhood (Courtenay, 2000). Thus, young men who want to emphasise their masculinity may perceive certain health behaviours through the prism of gender stereotypes, and therefore consider a healthy diet as typically female behaviour. Consequently, despite their awareness of the importance of proper nutrition for their health, these men may choose less favourable nutrition options (Courtenay, 2000). In our studies, paternal accepting attitude positively influenced healthy eating habits of young men, and this relationship was further mediated by self-efficacy. Paternal accepting attitude and the sense of agency (as paternal accepting attitude influenced self-efficacy) could be conducive to building a positive self-image as a man. Thus, perhaps engaging in health behaviours typically attributed to women is seen as less threatening to their masculinity. The quality of the father-son relationship may be related to the boys' masculine identification (Mussen \& Distler, 1959) and reduce adolescent risk behaviours (Zimmerman, Salem, \& Notaro, 2000).

In our study, the only health behaviour among female participants predicted by perceived parental attitudes was positive mental attitude. Positive mental attitude is a factor that, according to Juczyński (2009), is related to one's ability to avoid stressful and emotionally challenging situations, and preserve positive mood and thinking. Maintaining psychological well-being and emotional hygiene translates itself into positive outcomes in physical health and greater ability to recover from illnesses (Thayer, Åhs, Fredrikson, Sollers, \& Wager, 2012). Nonetheless, among female participants no other health behaviours were predicted by perceived parental attitudes, which is a result that varies from previous research that, for instance, demonstrated that healthy dieting (e.g. fruit and vegetable intake) in adolescent girls is positively associated with close emotional relationship with the father (Berge et al., 2010), and negatively associated with the mother's overprotective parental attitude (Toda, Kawai, Takeo, Rokutan, \& Morimoto, 2008). In our study, both mother's and father's perceived parental attitudes were found to play a significant role in predicting positive mental attitude of female participants, namely, accepting and autonomy granting maternal and paternal parental attitudes. This result is in line with previous research indicating the importance of both parents' emotional closeness and acceptance for psychological wellbeing of their offspring in childhood and adulthood (e.g. Rohner et al., 2005). Moreover, both the father-daughter and mother-daughter relationship determine an identity exploration process for adolescent girls, and a father-son relationship for teenage boys (Grotevant \& Cooper, 1985). Thus, we assume that for girls and young women, both the father and mother play important roles as behaviour models, sources of feedback, and agents motivating active exploration, independence, and self-care in the process of their psychological development. Mothers are possibly female role models for their daughters, providing direct and indirect instructions on certain behaviours and attitudes (Grotevant \& Cooper, 1985). Fathers provide feedback on whether presented behaviours are accepted, which contributes to their daughters' self-perception (Perkins, 2001), achievement motivation (Cooper, 2009), and lower levels of distress (Byrd-Craven, Auer, Granger, \& Massey, 2012).

\section{LIMITATIONS}

The results of our study should be considered in the context of certain limitations. The first is a small sample size (147 emerging adults, 101 female and 46 male participants), which is the reason why our results cannot be generalised into the whole population of emerging adults (1). Furthermore, the small sample reduces the statistical power to identify smaller effects, so there is a risk that some significant phenomena between variables will not be observed (Rehbein \& Baier, 2013). Thus, future research requires a greater number of participants, especially male ones, whose number in this study was lower than that of women. Another important limitation is the participation of students of social sciences (2). In future studies a wider group of emerging adults should be examined, and not limited to a single faculty or university students in general. In order to reduce the homogeneity of the respondents, it would be necessary to include emerging adults who did not enter higher education, and have already entered a job market. Another limitation of this study is its cross-sectional character (3). As a result, the results of the study do not inform about the course of the development of health behaviours and how they are influenced at the subsequent stages of childhood by the mother, the father, and their parental attitude. We suggest performing a longitudinal study in which children would be followed for several years. Thus, the process of the formation of their health behaviours could be observed and potential influencing factors (e.g. coping skills and self-regulation) measured several times. Furthermore, it would be crucial to observe and gather data about the roles of the mother and the father in health behaviour in the context of gender identity development and the development of views regarding masculinity and
Health behaviours in emerging adulthood and the mediating role of self-efficacy 
femininity, especially among the male participants. As our results suggested, also the quality of relationships with the opposite-sex parent and its role in health behaviour development should be investigated. Socioeconomic factors, including family type, wealth or health status, should also be considered because these factors may have an influence on the behaviour and attitude of parents towards their children (Hoff, Laursen, \& Tardiff, 2002).

Anna Maria Jankowska, Marta Łockiewicz,

Dorota

Dykalska-Bieck, Ariadna Łada, Weronika Owoc, Dawid

Stańczykowski

\section{CONCLUSIONS}

We found that, as expected, perceived parental attitudes predicted health behaviour for both male and female participants, and some of these associations were mediated by self-efficacy. The most pronounced relationships were found between accepting and autonomy granting maternal and paternal parental attitudes and positive health attitude (of both male and female participants), preventive behaviours, and healthy eating habits (of male participants).

In the case of female respondents in emerging adulthood, we observed that perceiving both of their parents as accepting and autonomy-granting, and fathers as consequent (less impulsive, unpredictable, and unstable) boosted their positive mental attitude. Interestingly, no other health behaviour was determined by the perceived mother's or father's parental attitudes in female participants. Self-efficacy mediated the relationship between perceived attitudes of accepting and autonomy granting of mothers and positive mental attitude of young female respondents during emerging adulthood.

In the case of male respondents in emerging adulthood, we observed that the participants who perceived their fathers as more accepting and autonomy granting more frequently declared the usage of preventive behaviours, having healthy eating habits, and manifesting a more positive mental attitude. Additionally, the perceived level of paternal demanding attitude influenced preventive behaviours - the less the father was perceived as demanding and controlling, the more often the male emerging adults reported taking preventive measures. In the case of the mother's parental attitudes, only inconsequent attitude determined lower results in health practices, i.e. the respondents were less likely to undertake daily physical activity and had worse sleeping habits. Self-efficacy mediated the relationship between perceived paternal accepting attitude and positive mental attitude and healthy eating habits.

Our results show the importance of perceived parental attitudes for young adults' lifestyle choices. Parents who accept their children unconditionally and give them autonomy equip them with positive mental attitudes that will help them maintain a healthy lifestyle, and increase their quality of life.

\section{REFERENCES}

Anderson, E. S., Winett, R. A., \& Wojcik, J. R. (2007). Self-regulation, self-efficacy, outcome expectations, and social support: Social cognitive theory and nutrition behavior. Annals of Behavioral Medicine, 34, 304-12. doi: 10.1007/BF02874555

Arnett, J. J. (2000). Emerging adulthood: A theory of development from the late teens through the twenties. American Psychologist, 55, 469-480. doi: 10.1037/0003-066X.55.5.469

Arnett, J. J. (2004). Emerging Adulthood: The Winding Road from the Late Teens Through the Twenties. Oxford: University Press.

Arnett, J. J. (2013). Adolescence and Emerging Adulthood. A Cultural Approach (4 ${ }^{\text {th }}$ ed.). New York: Pearson.

Bandura, A. (1993). Perceived Self-Efficacy in Cognitive Development and Functioning. Educational Psychologist, 28, 117-148.

Bandura, A. (1997). Self-efficacy: The exercise of control. New York: Freeman.

Bandura, A., Caprara, G. V., Barbaranelli, C., Gerbino, M., \& Pastorelli, C. (2003). Role of affective self-regulatory efficacy in diverse spheres of psychosocial functioning. Child Development, 74, 769-782.

Berg, C. A., King, P. S., Butler, J. M., Pham, P., Palmer, D., \& Wiebe, D. J. (2011). Parental involvement and adolescents' diabetes management: The mediating role of self-efficacy and externalizing and internalizing behaviors. Journal of Pediatric Psychology, 36, 329-339. doi: 10.1093/jpepsy/jsq088

Berge, J. M., Wall, M., Loth, K., \& Neumark-Sztainer, D. (2010). Parenting style as a predictor of adolescent weight and weight-related behaviors. The Journal of Adolescent Health: Official Publication Of The Society For Adolescent Medicine, 46, 331-338. doi: 10.1016/j.jadohealth.2009.08.004

Beyers, W., \& Goossens, L. (2008). Dynamics of perceived parenting and identity formation in late adolescence. Journal of Adolescence, 31, 165-184. doi: 10.1016/j.adolescence.2007.04.003

Binay, S.., \& Yiğit, R. (2016). Relationship Between Adolescents' Health Promoting Lifestyle Behaviors and Self-Efficacy. Journal of Pediatric Research, 3, 180-186. doi: 10.4274/jpr. 18894

Bong, M. (2008). Effects of parent - Child relationships and classroom goal structures on motivation, help-seeking avoidance, and cheating. Journal of Experimental Education, 76, 191-217. doi: 10.3200/JEXE.76.2.191-217

Bradley-Geist, J. C., \& Olson-Buchanan, J. B. (2014). Helicopter parents: an examination of the correlates of over-parenting of college students. $E d-$ ucation and Training, 56, 314-328. doi: 10.1108/ET10-2012-0096 
Butler, J. M., Skinner, M., Gelfand, D., Berg C. A., \& Wiebe, D. J. (2007). Maternal parenting style and adjustment in adolescents with type I diabetes. Journal of Pediatric Psychology, 32, 1227-1237. doi: 10.1093/jpepsy/jsm065

Byrd-Craven, J., Auer, B. J., Granger, D. A., \& Massey, A. R. (2012). The father-daughter dance: The relationship between father-daughter relationship quality and daughters' stress response. Journal of Family Psychology, 26, 87. doi: 10.1002/(SICI)1098108X(200007)28:1<78::AID-EAT9>3.0.CO;2-N

Cohen, S. I., \& Burger, M. (2000). Partnering: A new approach to sexual and reproductive health. New York: United Nations Population Fund.

Collins, W. A., \& Laursen, B. (2006). Parent-adolescent relationship. In P. Noller \& J. A. Feeney (eds.), Close relationships: Functions, forms and processes (pp. 111125). Hove: Psychology Press/Taylor and Francis.

Cooper, S. M. (2009). Associations between father-daughter relationship quality and the academic engagement of African American adolescent girls: Self-esteem as a mediator? Journal of Black Psychology, 35, 495-516. doi: 10.1177/0095798409339185

Cooper, M. J., Wells, A., \& Todd, G. (2004). A cognitive model of bulimia nervosa. British Journal of Clinical Psychology, 43, 1-16. doi: 10.1348/ 014466504772812931

Courtenay, W. (1998). College men's health: An overview and a call to action. Journal of American College Health, 46, 279-290. doi: 10.1080/ 07448489809596004

Courtenay, W. (2000). Engendering Health: A Social Constructionist Examination of Men's Health Beliefs and Behaviors. Psychology of Men and Masculinity, 1, 4-15. doi: 10.1037/1524-9220.1.1.4

Crocetti, E., Scrignaro, M., Sica, L. S., \& Magrin, M. E. (2012). Correlates of identity configurations: three studies with adolescent and emerging adult cohorts. Journal of Youth and Adolescence, 41, 732748. doi: 10.1007/s10964-011-9702-2

Dishman, R. K., Motl, R. W., Saunders, R., Felton, G., Ward, D. S., Dowda, M., \& Pate, R. R. (2004). Self-efficacy partially mediates the effect of a schoolbased physical-activity intervention among adolescent girls. Preventive Medicine, 38, 628-636. doi: 10.1016/j.ypmed.2003.12.007

Donnelly, R., Renk, K., \& McKinney, C. (2013). Emerging adults' stress and health: The role of parent behaviors and cognitions. Child Psychiatry and Human Development, 44, 19-38. doi: 10.1007/ s10578-012-0309-y

DuBois, D. L., Felner, R. D., Sherman, M. D., \& Bull, C. A. (1994). Socioenvironmental experiences, self-esteem, and emotional/behavioral problems in early adolescence. American Journal of Community Psychology, 22, 371-397. doi: 10.1007/BF02506871
Dwyer, J. M., Chulak, T., Maitland, S., Allison, K. R., Lysy, D. C., Faulkner, G. J., \& Sheeshka, J. (2012). Adolescents' self-efficacy to overcome barriers to Physical Activity Scale. Research Quarterly for Exercise and Sport, 83, 513-521. doi: 10.1080/02701367.2012.10599140

El Ansari, W., Suominen, S., \& Samara, A. (2015). Eating Habits and Dietary Intake: Is Adherence to Dietary Guidelines Associated with Importance of Healthy Eating among Undergraduate University Students in Finland? Central European Journal of Public Health, 23, 306-313. doi: 10.21101/cejph. a4195

Francis, L., \& Susman, E. (2009). Self-regulation and Rapid Weight Gain in Children From Age 3 to 12 Years. Archives of Pediatrics and Adolescent Medicine, 163, 297-302. doi: 10.1001/archpediatrics.2008.579

Franzoi, S. L., Vasquez, K., Sparapani, E., Frost, K., Martin, J., \& Aebly, M. (2012). Exploring body comparison tendencies: women are self-critical whereas men are self-hopeful. Psychology of Women Quarterly, 36, 99-109. doi: 10.1177/0361684311427028

Frydenberg, E., \& Lewis, R. (2009). The relationship between problem-solving efficacy and coping amongst Australian adolescents. British Journal of Guidance and Counselling, 37, 51-64. doi: 10.1080/03069880802534054

Furstenberg, F. F. (2006). Growing up healthy: Are adolescents the right target group? Journal of Adolescent Health, 39, 303-304. doi: 10.1016/j. jadohealth.2006.06.009

Gokee-LaRose, J., Gorin, A. A., \& Wing, R. R. (2009). Behavioral self-regulation for weight loss in young adults: a randomized controlled trial. International Journal of Behavioral Nutrition and Physical Activity, 6, 1-9. doi: 10.1186/1479-5868-6-10

Goldschmidt, A. B., Wall, M. M., \& Zhang, J. (2016). Overeating and Binge Eating in Emerging Adulthood: 10-Year Stability and Risk Factors. Developmental Psychology, 52, 475-483. doi: 10.1037/ dev0000086

Grotevant, H. D., \& Cooper, C. R. (1985). Patterns of Interaction in Family Relationships and the Development of Identity Exploration in Adolescence. Child Development, 56, 415-428. doi: 10.1111/14678624.ep7251638

Hayes, A. F. (2013). Introduction to mediation, moderation, and conditional process analysis: $A$ regression-based approach. New York, NY: The Guilford Press.

Helgeson, V. S., Honcharuk, E., Becker, D., Escobar, O., \& Siminerio, L. A. (2011). Focus on blood glucose monitoring: Relation to glycmeic control and determinants of frequency. Pediatric Diabetes, 12, 25-30. doi: 10.1111lj.1399-5448.2010.00663.x

Helgeson, V. S., Reynolds, K. A., Snyder, P. R., Palladino, D. K., Becker, D. J., Siminerio, L., \& Escobar, O.
Health behaviours in emerging adulthood and the mediating role of self-efficacy 
(2013). Characterizing the transition from paediatric to adult care among emerging adults with Type 1 diabetes. Diabetic Medicine, 30, 610-615. doi: $10.1111 /$ dme.12067

Hochhausen, N., Altmaier, E., McQuellon, R., Davies, S., Papadopolous, E., Carter, S., \& Henslee-Downey, J. (2007). Social support, optimism, and self-efficacy predict physical and emotional well-being after bone marrow transplantation. Journal of Psychosocial Oncology, 25, 87-101. doi: 10.1300/J077v25n01_05

Anna Maria Jankowska,

Marta Łockiewicz, Dorota

Dykalska-Bieck, Ariadna Łada, Weronika Owoc, Dawid

Stańczykowski

Hoff, E., Laursen, B., \& Tardif, T. (2002). SocioecoJersey: Lawrence Erlbaum.

Ingoldsby, B., Schvaneveldt, P., Supple, A., \& Bush, K. (2004). The Relationship Between Parenting Benomic status and parenting. In M. H. Bornstein (ed.), Handbook of parenting: Vol. 2. Biology and ecology of parenting (pp. 231-252). Mahwah, New haviors and Adolescent Achievement and Self-Efficacy in Chile and Ecuador. Marriage and Family Review, 35, 139-159. doi: 10.1300/J002v35n03_08

Jackson, L. M., Pratt, M. W., Hunsberger, B., \& Pancer, S. M. (2005). Optimism as a mediator of the relation between perceived parental authoritativeness and adjustment among adolescents: Finding the sunny side of the street. Social Development, 14, 273-304. doi: 10.1111/j.1467-9507.2005.00302.x

Janssen, I., Katzmarzyk, P. T., Boyce, W. F., King, M. A., \& Pickett, W. (2004). Overweight and obesity in Canadian adolescents and their associations with dietary habits and physical activity patterns. Journal of Adolescent Health, 35, 360-367. doi: 10.1016/j.jadohealth.2003.11.095

Joyce, P. R., Sellman, D., Wells, E., Frampton, C. M., Bushnell, J. A., Oakley-Browne, M., \& Hornblow, A. R. (1994). Parental bonding in men with alcohol disorders: a relationship with conduct disorder. The Australian and New Zealand Journal of Psychiatry, 28, 405-411. doi: 10.3109/ 00048679409075866

Juczyński, Z. (2009). Narzędzia pomiaru w promocji $i$ psychologii zdrowia [Instruments for measurements in health promotion and psychology]. Warszawa: Pracownia Testów Psychologicznych Polskiego Towarzystwa Psychologicznego.

Kanter-Agliata, A., \& Renk, K. (2009). College Students' Affective Distress: The Role of Expectation Discrepancies and Communication. Journal of Child and Family Studies, 18, 396-411. doi: 10.1007/ s10826-008-9244-8

Kessler, R. C., Mickelson, K. D., Walters, E. E., Zhao, S., \& Hamilton, L. (2004). Age and depression in the MIDUS Survey. In O. G Brim., C. D. Ryff, \& R. C. Kessler (eds.), How healthy are we? A national study of well-being at midlife (pp. 227-251). Chicago: The University of Chicago Press.

Khaleque, A., \& Rohner, R. P. (2002). Perceived Parental Acceptance-Rejection and Psychological
Adjustment: A Meta-Analysis of Cross-Cultural and Intracultural Studies. Journal of Marriage and Family, 64, 54-64. doi: 10.1111/j.17413737.2002.00054.x

Klassen, R. M., \& Chiu, M. M. (2010). Effects on Teachers' Self-Efficacy and Job Satisfaction: Teacher Gender, Years of Experience, and Job Stress. Journal of Educational Psychology, 102, 741-756. doi: 10.1037/a0019237

Klein-Hessling, J., Lohaus, A., \& Ball, J. (2005). Psychological predictors of health-related behaviour in children. Psychology, Health and Medicine, 10, 31-43. doi: 10.1080/13548500512331315343

Kremers, S. P., Brug, J., de Vries, H., \& Engels, R. C. (2003). Parenting style and adolescent fruit consumption. Appetite, 41, 43-50. doi: 10.1016/S01956663(03)00038-2

Kroger, J., Martinussen, M., \& Marcia, J. (2010). Identity status change during adolescence and young adulthood: A meta-analysis. Journal of Adolescence, 33, 683-698. doi: 10.1016/j.adolescence.2009.11.002

Kuendig, H., \& Kuntsche, E. (2006). Family bonding and adolescent alcohol use: moderating effect of living with excessive drinking parents. Alcohol and Alcoholism, 41, 464-471. doi: 10.1093/alcalc/ ag 1018

Larzelere, R. E., Morris, A. S., \& Harrist, A. W. (2013). Authoritative parenting: Synthesizing nurturance and discipline for optimal child development. Washington, DC: American Psychological Association. doi: 10.1037/13948-000

Lipowska, M., Lipowski, M., \& Pawlicka, P. (2016). "Daughter and son: a completely different story"? Gender as a moderator of the relationship between sexism and parental attitudes. Health Psychology Report, 4, 224-236. doi: 10.5114/hpr. 2016.62221

Lord, S., Eccles, J., \& Mccarthy, K. (1994). Surviving the Junior High School Transition Family Processes and Self-Perceptions as Protective and Risk Factors. The Journal of Early Adolescence, 14, 162199. doi: $10.1177 / 027243169401400205$

Luszczynska, A., \& Schwarzer, R. (2003). Planning and self-efficacy in the adoption and maintenance of breast self-examination: A longitudinal study on self-regulatory cognitions. Psychology and Health, 18, 93-108. doi: 10.1080/0887044021000019358

Luszczynska, A., \& Schwarzer, R. (2005). Social-cognitive theory. In M. Conner \& P. Norman (eds.), Predicting health behavior (pp. 127-169). Buckingham: Open University Press.

Lytle, L. A., Varnell, S., Murray, D. M., Story, M., Perry, C., Birnbaum, A. S., \& Kubik, M. Y. (2003). Predicting adolescents' intake of fruits and vegetables. Journal of Nutrition Education and Behavior, 35, 170-175. doi: 10.1016/S1499-4046(06)60331-X

Mohamadian, H., \& Ghannaee Arani, M. (2014). Factors predicting the physical activity behavior of 
female adolescents: A test of the health promotion model. Journal of Preventive Medicine and Public Health, 47, 64-71. doi: 10.3961/jpmph.2014.47.1.64

Mussen, P., \& Distler, L. (1959). Masculinity, identification, and father-son relationships. Journal of Abnormal and Social Psychology, 59, 350-356. doi: 10.1037/h0044529

Niemeier, B. S., Duan, Y. P., Shang, B. R., \& Yang, J. (2017). Parental influences on weight-related health behaviors in western and eastern cultures. Child: care, health and development, 43, 259266. doi: $10.1111 /$ cch. 12438

Nelson, L. J., Padilla-Walker, L. M., \& Nielson, M. G. (2015). Is hovering smothering or loving? An examination of parental warmth as a moderator of relations between helicopter parenting and emerging adults' indices of adjustment. Emerging Adulthood, 3, 282-285. doi: 10.1177/2167696815576458

Niditch, L., \& Varela, R. (2012). Perceptions of Parenting, Emotional Self-Efficacy and Anxiety in Youth: Test of a Mediational Model. Child and Youth Care Forum, 41, 21-35. doi: 10.1007/s10566-011-9150-x

Odenweller, K., Booth-Butterfield, M., \& Weber, K. (2014). Investigating Helicopter Parenting, Family Environments, and Relational Outcomes for Millennials. Communication Studies, 65, 407-425. doi: 10.1080/10510974.2013.811434

Perkins, R. M. (2001). The father-daughter relationship: Familial interactions that impact a daughter's style of life. College student journal, 35, 616-627.

Piotrowski, K., Brzezińska, A. I., \& Pietrzak, J. (2013). Four statuses of adulthood: Adult roles, psychosocial maturity and identity formation in emerging adulthood. Health Psychology Report, 1, 152-162. doi: 10.5114/hpr.2013.40469

Plopa, M. (2008). Więzi w matżeństwie i rodzinie. Metody badań [Marriage and family bonds. Research methods]. Kraków: Oficyna Wydawnicza Impuls.

Pomerantz, E., \& Eaton, M. (2001). Maternal intrusive support in the academic context: Transactional socialization processes. Developmental Psychology, 37, 174-186. doi: 10.1037/0012-1649.37.2.174

Posadzki, P., Stockl, S., Musonda, P., \& Tsouroufli, M. (2010). A mixed-method approach to sense of coherence, health behaviors, self-efficacy and optimism: Towards the operationalization of positive health attitudes. Scandinavian Journal of Psychology, 51, 246-252. doi: 10.1111/j.1467-9450.2009.00764.x

Pulerwitz, J., \& Barker, G. (2008). Measuring attitudes toward gender norms among young men in Brazil: Development and psychometric evaluation of the GEM scale. Men and Masculinities, 10, 322-338. doi: $10.1177 / 1097184 X 06298778$

Ray, C., Kalland, M., Lehto, R., \& Roos, E. (2013). Does parental warmth and responsiveness moderate the associations between parenting practices and children's health-related behaviors? Journal of nutrition education and behavior, 45, 602-610. doi: 10.1016/j.jneb.2013.04.001
Reed, K., Duncan, J. M., Lucier-Greer, M., Fixelle, C., \& Ferraro, A. J. (2016). Helicopter parenting and emerging adult self-efficacy: Implications for mental and physical health. Journal of Child and Family Studies, 25, 3136-3149. doi: 10.1007/s10826016-0466-x

Rehbein, F., \& Baier, D. (2013). Family-, media-, and school-related risk factors of video game addiction: A 5-year longitudinal study. Journal of Media Psychology, 25, 118-128. doi: 10.1027/1864-1105/ a000093

Riggs, N., Sakuma, K., \& Pentz, M. (2007). Preventing risk for obesity by promoting self-regulation and decision-making skills: Pilot results from the PATHWAYS to health program (PATHWAYS). Evaluation Review, 31, 287-310. doi: 10.1177/0193841X06297243

Rohner, R., Khaleque, A., \& Cournoyer, D. (2005). Parental acceptance-rejection: Theory, methods, cross-cultural evidence, and implications. Ethos, 33, 299-334. doi: 10.1525/eth.2005.33.3.299

Russek, L., \& Schwartz, G. (1997). Feelings of parental caring predict health status in midlife: A 35year follow-up of the Harvard Mastery of Stress Study. Journal of Behavioral Medicine, 20, 1-13. doi: 10.1023/A:1025525428213

Schwarzer, R. (2008). Modeling health behavior change: How to predict and modify the adoption and maintenance of health behaviors. Applied Psychology, 57, 1-29. doi: 10.1111/j.1464-0597.2007.00325.x

Schwarzer, R., \& Jerusalem, M. (1995). Generalized self-efficacy scale. In J. Weinman, S. Wright, $\&$ M. Johnston (eds.), Measures in health psychology: A user's portfolio causal and control beliefs (pp. 35-37). Windsor, UK: NFER-NELSON.

Schwarzer, R., \& Renner, B. (2000). Social-cognitive predictors of health behavior: Action self-efficacy and coping self-efficacy. Health Psychology, 19, 487-495. doi: 10.1037//0278-6133.19.5.487

Sęk, H. (2000). Znaczenie zachowań zdrowotnych [The importance of health behavior]. In K. de Walden-Gałuszko (ed.), Psychoonkologia [Psychooncology] (pp. 12-13). Kraków: Biblioteka Psychiatrii Polskiej.

Shanahan, M. J. (2000). Pathways to adulthood in changing societies: Variability and mechanisms in life course perspective. Annual Review of Sociology, 26, 667-692. doi: 10.1146/annurev.soc.26.1.667

Shorer, M., David, R., Schoenberg-Taz, M., LevaviLavi, I., Phillip, M., \& Meyerovitch, J. (2011). Role of parenting style in achieving metabolic control in adolescents with type 1 diabetes. Diabetes Care, 34, 1735-1737. doi: 10.2337/dc10-1602

Stolz, H., Barber, B., \& Olsen, J. (2005). Toward disentangling fathering and mothering: An assessment of relative importance. Journal of Marriage and Family, 67, 1076-1092. doi: 10.1111/j.17413737.2005.00195.x
Health behaviours in emerging adulthood and the mediating role of self-efficacy 
Substance Abuse and Mental Health Services Administration. (2011). Results from the $2011 \mathrm{Na}$ tional Survey on Drug Use and Health: Summary of National Findings NSDUH. Rockville, MD: Substance Abuse and Mental Health Services Administration. Retrieved from http://www.samhsa.gov/ data/nsduh/2k10nsduh/2k10results.htm

Thayer, J. F., Åhs, F., Fredrikson, M., Sollers, J. J., \& Wager, T. D. (2012). A meta-analysis of heart rate variability and neuroimaging studies: implications for heart rate variability as a marker of
Anna Maria Jankowska, Marta Łockiewicz, Dorota

Dykalska-Bieck, Ariadna Łada, Weronika Owoc, Dawid

Stańczykowski stress and health. Neuroscience and Biobehavioral Reviews, 36, 747-756. doi.org/10.1016/j.neubiorev.2011.11.009

Thomas, C., Hypponen, E., \& Power, C. (2008). Obesity and type 2 diabetes risk in midadult life: The role of childhood adversity. Pediatrics, 121, 12401249. doi: 10.1542/peds.2007-2403

Toda, M., Kawai, T., Takeo, K., Rokutan, K., \& Morimoto, K. (2008). Parental rearing attitudes and health-related lifestyle of university students. Social Behavior and Personality, 36, 551-558. doi: 10.2224/sbp.2008.36.4.551

Trzesniewski, K., Donnellan, M., Moffitt, T., Robins, R., Poulton, R., \& Caspi, A. (2006). Low self-esteem during adolescence predicts poor health, criminal behavior, and limited economic prospects during adulthood. Developmental Psychology, 42, 381390. doi: 10.1037/0012-1649.42.2.381

Turner, H. M., Rose, K. S., \& Cooper, M. J. (2005). Schema and parental bonding in overweight and nonoverweight female adolescents. International Journal of Obesity, 29, 381-387. doi: 10.1038/ sj.ijo.0802915

van der Vorst, H., Engels, R. C., Meeus, W., \& Dekovic, M. (2006). Parental attachment, parental control, and early development of alcohol use: A longitudinal study. Psychology of Addictive Behaviors, 20, 107-116. doi: 10.1037/0893-164X.20.2.107

Wardle, J., Haase, A., Steptoe, A., Nillapun, M., Jonwutiwes, K., \& Bellisle, F. (2004). Gender Differences in Food Choice: The Contribution of Health Beliefs and Dieting. Annals of Behavioral Medicine, 27, 107-116.

Weiner, L. H., Roloff, M. E., \& Pusateri, K. B. (2014). Role reversal: When emerging adults initiate health confrontations with their parents. Emerging Adulthood, 2, 246-256. doi: 10.1177/ 2167696814550842

Wienert, J., Kuhlmann, T., \& Lippke, S. (2015). Direct effects of a domain-specific subjective age measure on self-reported physical activity - Is it more important how old you are or how old you feel? Health Psychology Report, 3, 131-139. doi: 10.5114/ hpr.2015.51450

Wissink, I. B., Dekovic, M., \& Meijer, A. M. (2006). Parenting behavior, quality of the parent-adolescent relationship, and adolescent functioning in four ethnic groups. Journal of Early Adolescence, 26, 133-159. doi: 10.1177/0272431605285718

Wojtczak, A. (2009). Zdrowie publiczne wyzwaniem dla systemów zdrowia XXI wieku [Public health as a challenge for XXI century health systems]. Warszawa: Wydawnictwo Lekarskie PZWL.

Wolfradt, U., Hempel, S., \& Miles, J. N. (2003). Perceived parenting styles, depersonalisation, anxiety and coping behaviour in adolescents. Personality and Individual Differences, 34, 521-532. doi: 10.1016/S0191-8869(02)00092-2

Woynarowska, B. (2010). Czynniki warunkujące zdrowie i dbałość o zdrowie [Factors determining health and health practices]. In B. Woynarowska (ed.), Edukacja zdrowotna [Health education] (pp. 44-61). Warszawa: Wydawnictwo Naukowe PWN.

Zhou, G., Sun, C., Knoll, N., Hamilton, K., \& Schwarzer, R. (2015). Self-efficacy, planning and action control in an oral self-care intervention. Health Education Research, 30, 671-681. doi: 10.1093/her/cyv032

Zimmerman, M. A., Salem, D. A., \& Notaro, P. C. (2000). Make room for daddy II: The positive effects of fathers' role in adolescent development. In R. Taylor \& L. Wang (eds.), Resilience across Contexts: Family, Work, Culture and Community (pp. 233-253). Mahwah, New Jersey: Lawrence Erlbaum. 